\title{
WIDESPREAD SEROUS MEMBRANE INVOLVEMENT BY RHEUMATOID NODULES
}

\author{
BY \\ PHILIP ELLMAN, LEON CUDKOWICZ, AND J. STANLEY ELWOOD \\ From the Rheumatism Unit and Department of Pathology, St. Stephen's Hospital, London
}

(RECEIVED FOR PUBLICATION FEBRUARY 4, 1954)

The characteristic cutaneous rheumatoid nodule, described fully by Collins (1937) and Bennett, Zeller, and Bauer (1940), is composed of a central area of fibrinoid necrosis around which develops an encircling corona of closely packed mesenchymal cells, the great majority of which appear to be fibroblasts (Collins, 1937), and external to this is a zone of inflammatory tissue.

Lesions with similar histological features occur in the synovial membranes, and have been described involving serous membranes such as the pleura (Bennett et al., 1940 ; Baggenstoss and Rosenberg, 1943 ; Gruenwald, 1948), and Raven, Weber, and Price (1948), in whose case the peritoneum was also involved. Rheumatoid lesions have been known for some time to involve the pericardium (Baggenstoss and Rosenberg, 1944 ; Feiring, 1945 ; Clark and Bauer, 1947, 1948 ; Raven et al., 1948) the myocardium (Clark and Bauer, 1948), the ring and cusps of the mitral and aortic valves (Grzimek, 1932 ; Baggenstoss and Rosenberg, 1941 ; Bywaters, 1950; Sokoloff, 1953a), the aortic valve (Pirani and Bennett, 1951 ; Bauer, Clark, and Külka, 1951), and the tricuspid valve (Baggenstoss and Rosenberg, 1941; Gruenwald, 1948).

Ellman (1947) and Ellman and Ball (1948) have described interstitial involvement of the lung in rheumatoid disease.

It is therefore thought that the present case may be of interest as it illustrates the widespread clinical manifestations associated with rheumatoid lesions of the pericardium, myocardium, endocardium, all heart valves, sclera, visceral pleura, and dura mater. As far as can be ascertained involvement of the dura mater has not previously been recorded.

\section{Case Report}

J. S., a retired jeweller aged 63, was first seen in 1951 with a 17 years' history of rheumatoid disease affecting principally the knees, wrists, metacarpophalangeal joints, and ankles. In the last seven years of the illness the exacerbations of the joint swellings coincided with attacks of "bronchitis," dyspnoea, and purulent sputum. While these attacks lasted the joints were always swollen and painful ; and remissions, with a fall in the erythrocyte sedimentation rate, occurred as the chest symptoms subsided.

Before admission the patient suffered increasing dyspnoea, loss of weight, swollen and painful joints, crops of subcutaneous nodules, and a painful left eye.

The patient was an emaciated pale man; he was apyrexial and orthopnoeic. His left eye showed a patch of episcleritis on the lateral corneal-scleral margin with a raised nodule in the centre. Painful nodules 1 to $2 \mathrm{~cm}$. in diameter covered the external occipital protuberance, the left olecranon process, the ulnar borders of both forearms and the ischial tuberosities. The wrists, metacarpophalangeal joints, and the knees were very swollen.

The trachea was central and there was no finger clubbing. Clinical examination of the lungs showed dullness, and absent breath sounds over the left base with localized rales.

The jugular venous pressure was raised, the heart was slightly enlarged with the apex beat $4 \frac{1}{2}$ in. from the mid-sternal line. The sounds were normal; the blood pressure was $105 / 65 \mathrm{~mm}$. of mercury. The pulse rate was 45 and an electrocardiogram showed 2:1 heart block with right axis deviation.

The liver and spleen were not palpable.

The cranial nerves were normal and no abnormality was noted in muscular power and sensation apart from the wasting secondary to the arthritis. The reflexes and plantar responses were normal.

Radiology of the chest confirmed the cardiac enlargement, and cardioscopy showed this to be confined to the right ventricle. An effusion was present at the left base.

Thoracentesis showed a clear, straw-coloured fluid in which no malignant cells were seen, and cultures were sterile. Guinea-pig inoculation for tuberculosis was negative.

Analysis of urine and renal function tests were normal.

The erythrocyte sedimentation rate fluctuated throughout his stay in hospital between 80 and $100 \mathrm{~mm}$. per hour (Westergren). A haematological examination showed a mild hypochromic anaemia with a haemoglobin level between 10.6 and $11.3 \mathrm{~g} . \%$.

After a period of observation the patient was digitalized, and given " mersalyl" twice a week. This had no effect on the pleural effusion. It was then decided to try the effects of hormone therapy, and he received corti- 
sone, $100 \mathrm{mg}$. daily, over a period of 32 days. On this regime the joint swellings and nodules regressed, the dyspnoea became less distressing, and he could sleep on two pillows.

The dose of cortisone was gradually reduced to $25 \mathrm{mg}$. daily, and discontinued on the seventy-first day. The pleural effusion, however, remained uninfluenced. There was no change in the serum electrolytes, and at no time was oedema or a rise of jugular venous pressure noted.

The patient returned to his home and attended as an out-patient at regular intervals. Four months after cessation of cortisone no change in physical signs was noted and the radiology of the joints remained the same.

During the last two months of his life the patient began to suffer from episodes of loss of consciousness preceded by what appeared to be Jacksonian fits. He died at home following such an episode in May, 1953.

\section{Necropsy Findings}

The body was that of an emaciated old man showing multiple subcutaneous nodules about the elbows, neck, occiput, and ischial tuberosities.

Each pleural cavity contained about $500 \mathrm{ml}$. of thin, watery, yellowish fluid. The parietal and visceral pleura were covered with large masses of fibrin giving them a shaggy appearance, which was more marked over the lower lobes. On the visceral pleura, where it was not covered with fibrin, occasional small yellow nodules up to $3 \mathrm{~mm}$. in diameter were present.

The right lung weighed $620 \mathrm{~g}$. and the left $475 \mathrm{~g}$. There was a generalized chronic bronchitis with some mucopus in the bronchi. On section the lungs were emphysematous, but the striking feature was the presence of numerous spherical lesions, some quite small, others as large as 1 to $2 \mathrm{~cm}$. in diameter, scattered in the peripheral and sub-pleural parts of the lungs; none was found in the central parts. These lesions had a soft, cheese-like centre surrounded by collapsed and thickened lung parenchyma. The pleura was thickened by layers of fibrin up to $2 \mathrm{~cm}$. with an occasional abscess cavity in it.

The pericardial cavity was obliterated by dense fibrous tissue, and its two layers were torn apart with difficulty, revealing an abscess cavity filled with greenish pus in its posterior part.

The heart weighed $264 \mathrm{~g}$. and showed a flabby, soft, atrophic myocardium. There was some dilatation of the right ventricle. On opening the organ many nodules up to $0.5 \mathrm{~cm}$. in diameter were seen on the endocardium, especially that of the left auricle and ventricle close to the mitral and aortic valves; two similar nodules were present on one cusp of the tricuspid valve, and several on one cusp of the aortic and pulmonary valves and on both cusps of the mitral valve. Occasional similar lesions were found in the substance of the myocardium and also in the epicardium about the root of the aorta. There were no lesions in the interventricular septum.

Similar nodules were present in the intima of the ascending part of the aorta. A moderate degree of atheroma affected the abdominal part. No abnormality was noted in other large arteries examined.

The abdominal organs were normal apart from a small cortical infarct in the left kidney.

The only abnormality in the endocrine system was adenomatous hyperplasia of the left adrenal.

Nothing of note was seen in the lymphatic system.

The brain weighed $1,380 \mathrm{~g}$. The dura mater was $\vec{\circ}$ adherent to both cerebral hemispheres over the vertex, but was readily separated from the pia. In the $\vec{\omega}$

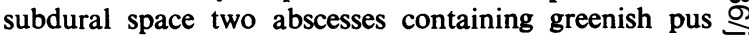
approximately $2 \times 1 \mathrm{~cm}$. were present on each side of $\overline{0} 0$ the falx. Minimal atheroma of the cerebral arteries was present but the brain itself was normal.

The subcutaneous nodules in the scalp and about the elbow varied from 1 to $2 \mathrm{~cm}$. in diameter and had a soft necrotic centre.

The joints examined showed thickening and hyper- trophy of the synovial membrane and erosion of the articular cartilage.

Pus taken from the various lesions grew only Proteus $\frac{c}{\omega}$ vulgaris, which was regarded as a post-mortem contaminant, because necropsy had been delayed for 24 hours $\vec{E}$ and the body had not been refrigerated.

Histology
Tissues removed at necropsy were fixed in formolsaline and stained with haematoxylin and eosin. Selected tissues were stained with phosphotungstic acid haemat- $\stackrel{0}{\circ}$ oxylin, Weigert's fibrin stain, Lendrum's modification of $\stackrel{\mathbb{Q}}{\varrho}$ Mallory's trichrome stain, periodic-acid-Schiff, and silver $\overrightarrow{\vec{O}}$ impregnation for reticulin fibrils. Gram's stain and $\frac{0}{3}$ Zieh!-Neelsen's stain for micro-organisms were also used.

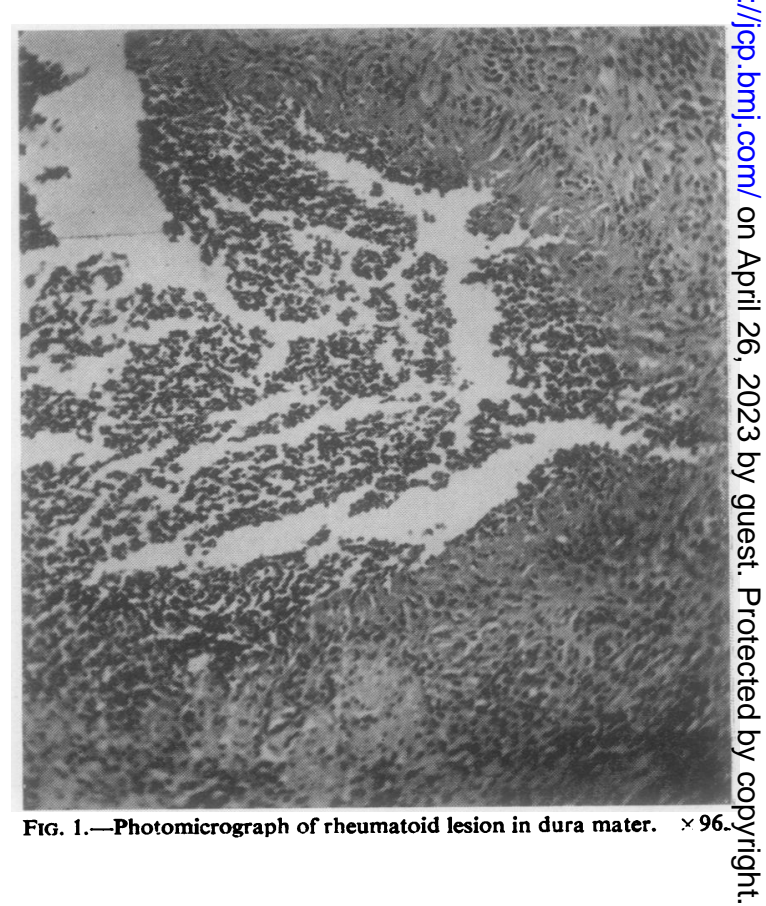




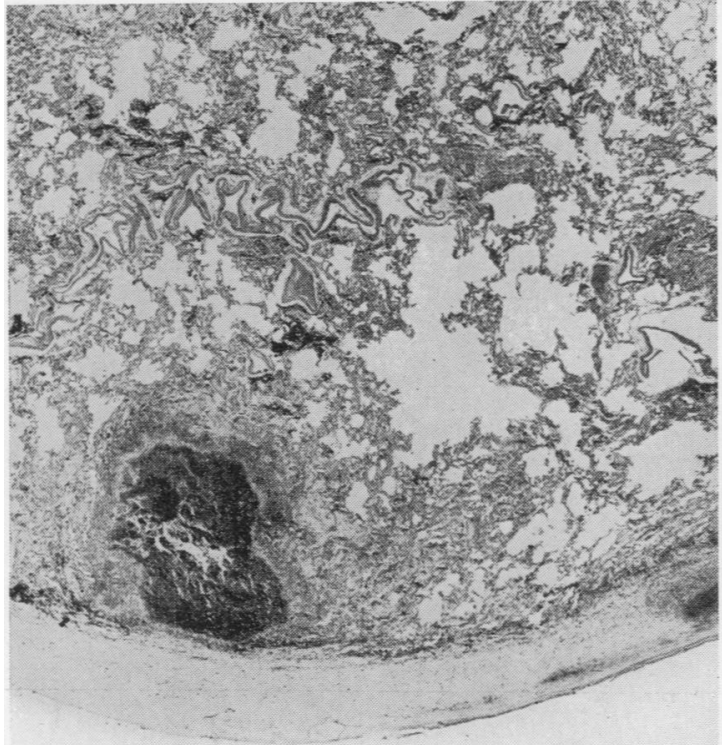

FIG. 2.-Photomicrograph of section from left lung showing thickened visceral pleura and rheumatoid lesion in adjacent lung $\times 6$.

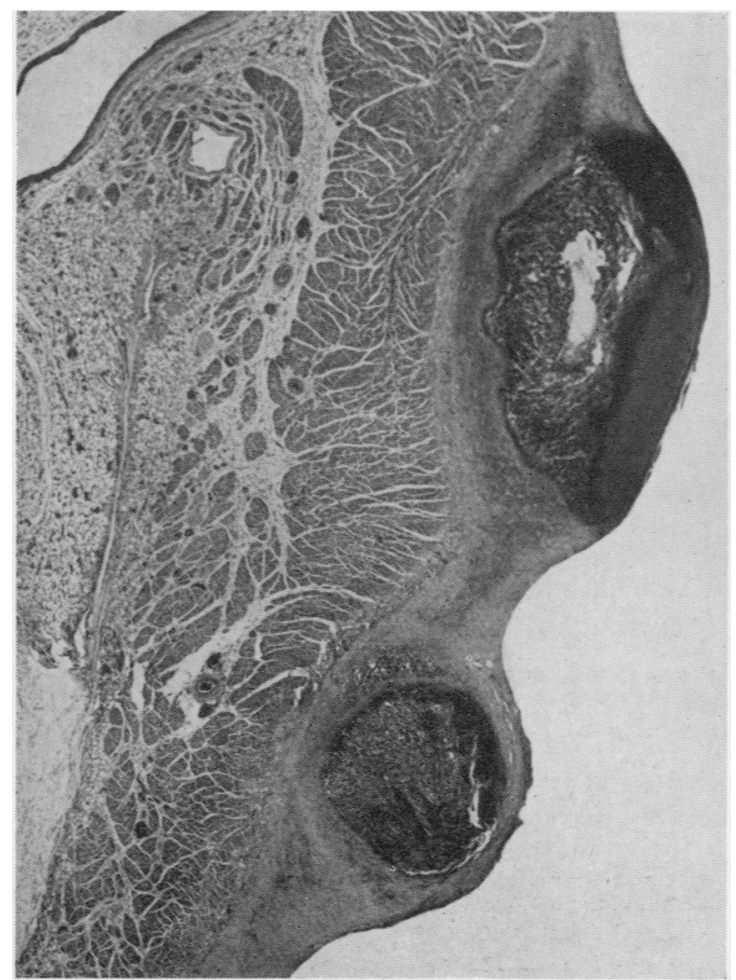

FIG. 3.-Photomicrograph of section of left auricular myocardium and endocardium showing two rheumatoid lesions in the endocardium. $\times 10$
In the spleen congestion and acute inflammation of the pulp with slight hyalinization of the Malphigian arterioles were observed.

The liver showed congestion and slight focal fatty change.

In the kidneys slight ischaemic fibrosis was seen.

A mediastinal lymph node revealed chronic inflammation.

Post-mortem autolysis and considerable adenomatous hyperplasia were present in the left adrenal.

In the dura mater (Fig. 1) generalized chronic inflammation of the cranial aspect was noted. The arachnoid surface of the dura was converted into granulation tissue in which were multiple rheumatoid lesions characterized by central necrosis and radially arranged elongated cells with pale nuclei and indistinct outlines. The central necrotic area was either amorphous and eosinophilic or showed pyknotic and fragmented nuclei, some of which resembled degenerating polymorphs. The radially arranged cells were surrounded by a zone of histiocytes, plasma cells, and lymphocytes.

The pleura (Fig. 2) was grossly thickened and showed much collagen moderately infiltrated with chronic inflammatory cells. Occasional rheumatoid lesions with degenerating cells in the central zone were present in the pleura and also in the lung adjacent to it. The alveoli near the lesion were collapsed, fibrosed, and showed

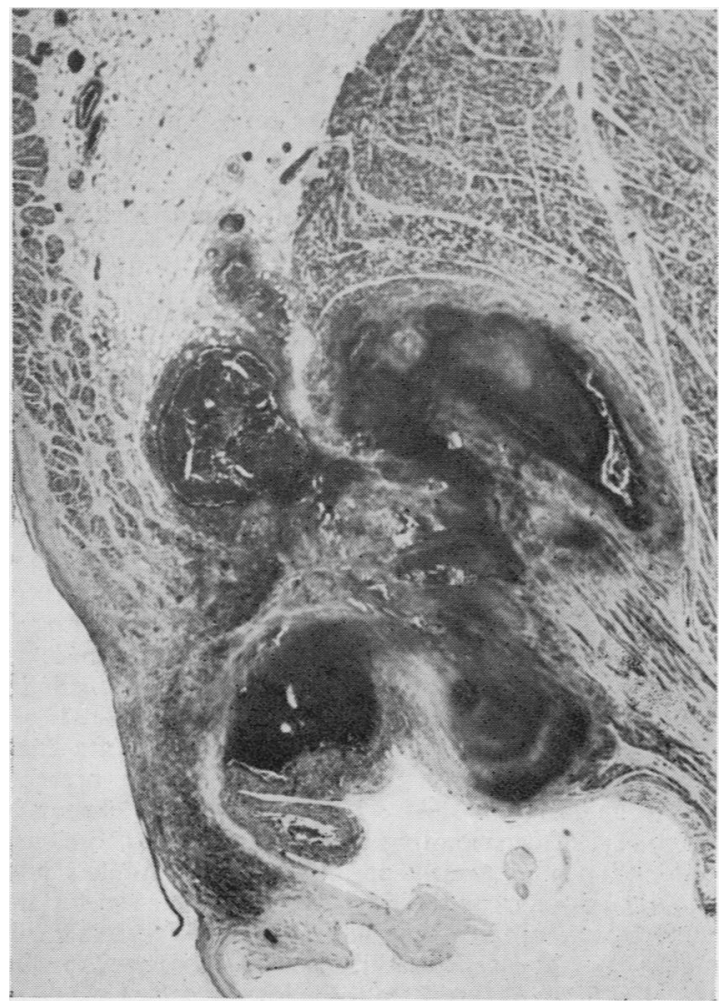

Fig. 4.-Photomicrograph of section of left ventricle showing rheumatoid lesions in myocardium. $\times 10$. 


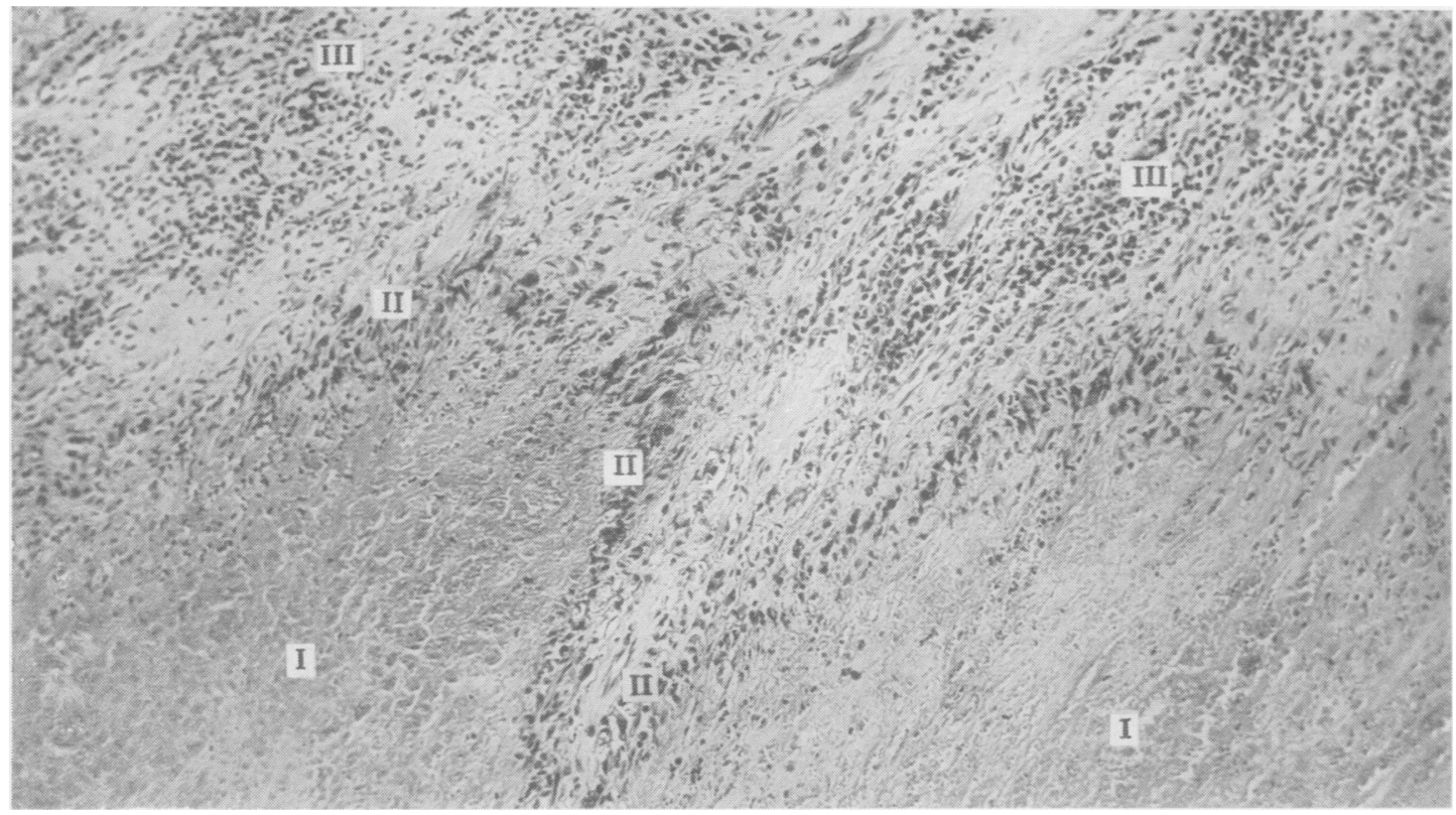

FIG. 5.-Photomicrograph of edge of rheumatoid lesion in myocardium of left ventricle showing (I) central necrotic zone, (II) intermediate zone of radially arranged elongated cell, (III) outer zone of chronic inflammatory cells. $\times 130$.

some subacute inflammation. Elsewhere in the lower lobes the alveoli showed generalized collapse, fibrosis, and subacute inflammatory change.

The pericardium showed dense fibrosis and a diffuse sparse infiltration of chronic inflammatory cells. Sections prepared from the abscess cavity in the posterior part of the pericardium showed typical rheumatoid lesions.

In the myocardium and valves (Figs. 3, 4, and 5) the rheumatoid lesions were sharply demarcated from the normal structures. Where they abutted on the endocardium the latter was undamaged and no ulceration was observed. The myocardium showed generalized cloudy swelling and fragmentation with some interstitial oedema; no abnormality was noted in the connective tissue between the muscle fibres or in the small arterioles.

The typical appearance of the rheumatoid lesion in this case may be summarized as follows. Three zones may be distinguished (Fig. 5): (1) a central necrotic zone ; (2) an intermediate zone of radially arranged elongated cells with pale nuclei and indistinct outlines; and (3) an outer zone of chronic inflammatory cells in which plasma cells are numerous.

The radially arranged cells of the intermediate zone show mitotic figures and giant cells are sometimes present. In the majority of lesions the central necrotic zone is composed of degenerating leucocytes, but an occasional one shows an intensely eosinophilic, structureless and slightly granular necrotic centre which does not stain with phosphotungstic acid haematoxylin, Weigert's fibrin stain; or Mallory's stain. Silver impregnation for reticulin fibres shows these to be interrupted at the edge of the lesion, and only an occasional fibril persists in the necrotic area (Fig. 6). The margin of the necrotic zone stains with the periodic-acid-Schiff technique.

The vasculature of the outer inflammatory zone was carefully examined by serial section, but no gross lesion

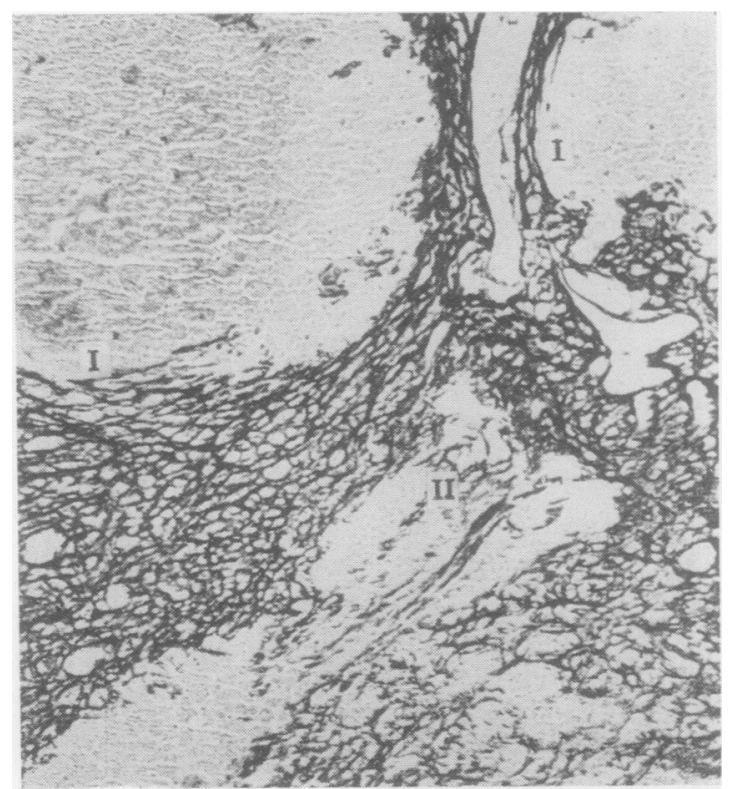

FIG. 6.-Photomicrograph of myocardium showing (I) interruption of reticulin fibrils at edge of the necrotic zone of the lesion and (II) persistence of an occasional fibril in the necrotic zone (Silver impregnation). $\quad \times 80$. 
was seen apart from some intimal thickening of the smaller arterioles. No remnants of vessels were observed in the central necrotic zone.

\section{Discussion}

The clinical interest of this case centres in the symptoms and signs produced by the widely scattered rheumatoid lesions.

During the patient's final admission the pleural effusion and the 2:1 heart block dominated the picture. Whilst in hospital it was presumed, in view of the many subcutaneous nodules (tuberculosis, malignant disease, and cardiac failure having been excluded), that both the effusion and the heart block might be related to rheumatoid lesions on the pleura and close to the bundle of His. The lack of response of both of these conditions to hormonal therapy, in spite of regression of the subcutaneous nodules, is of some interest. It was surprising to find such gross cardiac involvement when the only clinical finding was heart block. A similar discrepancy was noted by Baggenstoss and Rosenberg (1941). In their series 14 cases showed gross cardiac lesions at necropsy, but only seven had clinical signs. Although epileptiform fits of Jacksonian type were observed at the latter part. of the illness no cause for these was surmised, but the presence of rheumatoid lesions on the dura mater at necropsy suggests an obvious relationship.

The pleural effusion in this case is obviously related to the rheumatoid lesions on the pleura. It may be of interest in this respect that Robertson (1952) found four out of 58 pleural effusions in patients over the age of 40 to be due to "collagen diseases."

In this case many of the rheumatoid lesions showed pyknotic and fragmented nuclei in the central zone suggestive of degenerating polymorphs. This feature was also observed by Baggenstoss and Rosenberg (1944) and by Raven et al. (1948) and is to be regarded as a variant of the typical hyaline " fibrinoid" necrotic centre as described by Collins (1937) and Bennett et al. (1940).

It is probable that in this case the necrotic change in the lesions had progressed beyond the " fibrinoid " stage and complete necrosis had taken place ; this is evidenced by the relatively weak periodic acid Schiff reaction seen mainly in the marginal part of the necrotic zone of the lesions. The interruption of reticulin fibrils, as shown in Fig. 6, indicates that the necrotic lesion has developed in pre-formed collagen and not as an additional exudative lesion.

Although the necrobiotic lesion might be considered to have a superficial resemblance to tuber- culosis the palisaded cellular zone is essentially different from its tuberculous counterpart, and in appropriately stained sections no tubercle bacilli or other organisms were found.

The aetiology of the rheumatoid lesions cannot be stated with certainty ; two opposing theses are current in the literature. The relationship between vascular changes and nodule formation was first emphasized by Von Glahn and Pappenheimer (1926) in rheumatic fever, and Sokoloff (1953b) considers that the subcutaneous rheumatoid nodule results from occlusive lesions in the subcutaneous vasculature. This view is supported by Bennett et al. (1940) who found remnants of pre-existing blood vessels in the central necrotic zone of such rheumatoid nodules, and they emphasize the frequency of vascular changes in the peripheral inflammatory zone and even suggest that the necrosis may be partly due to infarction.

On the other hand Collins $(1937,1949)$ states that the fibrinoid degeneration arises in the proliferating mesenchymal cells of the nodule and "spreads outwards, encroaching first on the newly proliferated tissue and then on older structures, such as blood vessels and mature collagen bundles," and in his Fig. 4 (1937) this is well illustrated.

While it is admitted that vascular lesions may be difficult to demonstrate careful examination of many sections of rheumatoid lesions from this case failed to reveal any appearance suggestive of antecedent vascular changes; and in sections prepared from tissues not showing actual lesions no vascular changes were noted.

The observations made in this case do not illuminate the aetiology of these nodules, but the widespread distribution of the lesions emphasizes the protean nature of rheumatoid disease in its disseminated form.

\section{Summary}

A case of long-standing rheumatoid disease is described in which widespread rheumatoid lesions were associated with pleural effusions, heart block, and Jacksonian epilepsy. The histological appearances of the lesions in the visceral pleura, endocardium, pericardium, and dura mater resemble the well-known subcutaneous nodules of rheumatoid disease.

We wish to thank Dr. A. G. Signy, Director of the Group Laboratory, St. Mary Abbots Hospital, London, for helpful criticism of the manuscript, and Mr. J. E. Andrews, of the Southern Group Laboratory, London, for some of the photomicrographs. 


\section{REFERENCES}

Baggenstoss, A. H., and Rosenberg, E. F. (1941). Arch. intern. Med., 67, 241.

(1943). Arch. Path., Chicago, 35, 503.

(1944). Ibid., 37, 54.

Bauer, W., Clark, W. S., and Külka, J. P. (1951). Ann. rheum. Dis., $10,470$.

Bennett, G. A., Zeller, J. W., and Bauer, W. (1940). Arch. Path., Chicago, 30, 70.

Bywaters, E. G. L. (1950). Brit. Heart J., 12, 101.

Clark, W. S., and Bauer, W. (1947). Proc. Ann._Mtg. American Rheumatism Ass.

(1948). Ann. rheum. Dis., 7, 39.

Collins, D. H. (1937). J. Path. Bact., 45, 97.
Collins, D. H. (1949). The Pathology of Articular and Spinal Diseases, p. 192. Arnold, London.

Ellman, P. (1947). Proc. roy. Soc. Med., 40, 332.

- and Ball, R. E. (1948). Brit. med. J., 2, 816.

Feiring, W. (1945). N.Y. St. J. Med., 45, 1855.

Gruenwald, P. (1948). Arch. Path., Chicago, 46, 59.

Grzimek, N. (1932). Virchows Arch. path. Anat., 286, 286.

Pirani, C. L., and Bennett, G. A. (1951). Bull. Hosp. Jt Dis., N.Y., $12,335$.

Raven, R. W., Weber, F. Parkes, and Price, L. W. (1948). Ann. rheum. Dis., 7, 63.

Robertson, R. F. (1952). Brit. med. J., 1, 133.

Sokoloff, L. (1953a). Amer. Heart J., 45, 635.

(1953b). Lancet, 1, 1232.

Von Glahn, W. C., and Pappenheimer, A. M. (1926). Amer. J. Path., 2, 235. 